\title{
ESTUDO COMPARATIVO DAS ALTERAÇÕES DENTOESQUELÉTICAS DA MÁ-OCLUSÃO DE CLASSE II, 1a DIVISÃO DE ANGLE, NOS JOVENS SEM TRATAMENTO E NOS SUBMETIDOS A DOIS TIPOS DE APARELHOS ORTODÔNTICOS ${ }^{\dagger}$
}

\section{COMPARATIVE STUDY OF DENTOSKELETAL CHANGES IN UNTREATED CLASS II, DIVISION 1 MALOCCLUSIONS AND IN THOSE TREATED WITH TWO TYPES OF ORTHODONTIC APPLIANCES}

\author{
Liliana Ávila MALTAGLIATI* \\ José Fernando Castanha HENRIQUES** \\ Renato Rodrigues ALMEIDA*** \\ Marcos Roberto FREITAS**** \\ Arnaldo PINZAN****
}

\begin{abstract}
MALTAGLIATI, L. A.; HENRIQUES, J. F. C.; ALMEIDA, R. R.; FREITAS, M. R.; PINZAN, A. Estudo comparativo das alterações dentoesqueléticas da má-oclusão de Classe II, $1^{a}$ divisão de Angle, nos jovens sem tratamento e nos submetidos a dois tipos de aparelhos ortodônticos. Rev Odontol Univ São Paulo, n. 13, v. 4, p. 407-416, out./dez. 1999.
\end{abstract}

\begin{abstract}
A realização deste trabalho teve por objetivo comparar as alterações dentoesqueléticas da má-oclusão de Classe II, $1^{a}$ divisão de Angle sem tratamento com as tratadas por dois tipos de aparelhos ortodônticos. As radiografias cefalométricas em norma lateral iniciais e finais de um grupo controle e de dois experimentais, um tratado com o aparelho removivel conjugado à ancoragem extrabucal cervical e outro com a terapia ortodôntica fixa sem extrações e ancoragem extrabucal cervical, foram traçadas e submetidas ao teste estatístico. A análise dos resultados revelou que há pouca alteração do padrão de crescimento e que a altura facial ântero-inferior aumentou em todos os grupos. Não houve melhora significante da relação maxilomandibular no grupo controle, enquanto que, nos grupos tratados, a maxila foi retraída, com diminuição significante do ângulo ANB. As alterações dentoalveolares demonstraram que o aparelho utilizado no grupo 2 foi eficiente no controle vertical do crescimento da maxila e na extrusão dos dentes superiores posteriores e anteriores. Estes, em ambos os grupos tratados, foram movimentados para distal e palatino, respectivamente, levando à uma relação molar normal e à redução do trespasse horizontal aumentado. No grupo controle, no entanto, os dentes superiores e inferiores desenvolveram-se em uma direção ântero-inferior, mantendo as características da má-oclusão de Classe II, $1^{\text {aa }}$ divisão de Angle.
\end{abstract}

UNITERMOS: Ortodontia; Aparelhos ortodônticos; Maloclusão de Angle Classe II.

\section{INTRODUÇÃO}

Desde os primórdios da Ortodontia, o mau posicionamento dentário vem sendo discutido, procurando-se avaliar as causas e as características das desarmonias dentoesqueléticas com o propósito de conhecê-las, controlá-las e corrigi-las.
A má-oclusão de Classe II, não possui morfologia única que defina a estrutura facial. Várias são as relações horizontais e verticais, possuindo em comum, apenas a relação ântero-posterior dos arcos dentários, que pode variar desde uma retrusão mandibular, protrusão maxilar, até uma combinação destes fatores ${ }^{13}$. Frente a esta grande quan-

$\dagger$ Resumo de Dissertação de Mestrado.

*Aluna de Doutorado em Ortodontia; ** Professor Titular; *** Professor Assistente Doutor; **** Professores Associados - Disciplina de Ortodontia - Faculdade de Odontologia de Bauru - USP. 
MALTAGLIATI, L. A.; HENRIQUES, J. F. C.; ALMEIDA, R. R.; FREITAS, M. R.; PINZAN, A. Estudo comparativo das alterações dentoesqueléticas da má-oclusão de Classe II, $1^{a}$ divisão de Angle, nos jovens sem tratamento e nos submetidos a dois tipos de aparelhos ortodônticos. Rev Odontol Univ São Paulo, n. 13, v. 4, p. 407-416, out./dez. 1999.

tidade de variações, inúmeros são os aparelhos desenvolvidos de correção e de interceptação e, conseqüentemente, surge a preocupação em relação aos efeitos por eles produzidos, método de ação e período mais propício para a sua utilização.

A rareza de pesquisas apoiadas em grupos controle, sem tratamento, faz persistir os questionamentos sobre a ação dos aparelhos disponiveis. A possibilidade de acompanhamento longitudinal de pacientes sem tratamento que apresentam máoclusão é escassa e quando possível, sujeita a limites de pequena amostragem.

A oportunidade de reunir um grupo de pacientes com má-oclusão de Classe II, $1^{a}$ divisão, sem tratamento, acompanhados durante o período de dentadura mista tardia, motivou-nos à realização de um trabalho comparativo desse grupo com outros dois, submetidos ao tratamento com o aparelho removivel conjugado à ancoragem extrabucal e com a terapia ortodôntica fixa, com o intuito de avaliar, comparar e distinguir os efeitos produzidos pelos dois tipos de intervenção com aqueles que emanam do crescimento inerente da faixa etária em que se encontram os pacientes.

\section{REVISÃO DE LITERATURA Características da má-oclusão de Classe II, $1^{\text {a }}$ divisão}

O interesse pela sistematização das anomalias dentárias sempre esteve presente na ciência odontológica. A procura por um modelo de identificação e classificação das más-oclusões teve início ainda em meados do século XVIII, inicialmente pelos anatomistas e posteriormente pelos ortodontistas.

Com o advento do cefalostato por BROADBENT ${ }^{3}$ nos Estados Unidos e HOFRAT ${ }^{17}$ (1941) na Alemanha em 1931, os estudos cefalométricos se tornaram exeqüiveis, apontando para a existência de diversas formas de má-oclusão de Classe II, associadas com alterações de componentes esqueléticos e dentários.

Após separar as más-oclusões de Classe II em três categorias: dentária, dentofacial e facial, FISCHER ${ }^{12}$ (1950), estabeleceu que "há tantos padrões dentofaciais da Classe II, $1^{a}$ divisão, quanto os indivíduos que possuem essa má-oclusão".

Estudos do crescimento da má-oclusão de Classe II, $1^{a}$ divisão verificaram que o ponto $A$ não altera seu posicionamento ântero-posterior, mantendo os valores de SNA e a inclinação do plano pa- latino e os incisivos superiores e inferiores não apresentam modificações na sua inclinação. Ocorre uma taxa crescente de avanço mandibular com a idade e diminuição do ângulo ANB, tendendo à retificação do perfil.

As características dentoesqueléticas de cinqüenta pacientes com má-oclusão de Classe II, $1^{\text {a }}$ divisão foram analisadas por VALE; MARTINS ${ }^{27}$ (1987). Constataram que a posição da maxila apresenta-se bastante variável, com uma discreta tendência para o prognatismo e a mandíbula mostrou-se variando de normal para retrognática. Os incisivos superiores estão protruídos e os inferiores retruídos. A direção de crescimento desses pacientes denotou predominância do componente vertical.

Os resultados do estudo de CARTER ${ }^{6}$ (1987), mostraram que o ângulo SNA se manteve, assim como o plano palatino. Os incisivos superiores tenderam a inclinar para vestibular ligeiramente e a extruir. Os incisivos inferiores apresentaram uma pequena vestibularização para o sexo feminino e verticalização para o sexo masculino, extruindo assim como os molares superiores e inferiores, que também mesializaram.

DERRINGER ${ }^{8,9}$ (1990) afirmou que ocorre um aumento insignificante dos ângulos SNA e SNB. Já a altura facial ântero-inferior aumenta significantemente com o crescimento. Os primeiros molares superiores, foram movimentados para mesial, ocorrendo aumento da sua inclinação axial para mesial acompanhado de extrusão. Os molares inferiores também foram movimentados para mesial porém com verticalização acompanhada de extrusão. Os incisivos superiores e inferiores apresentaram um ligeiro aumento da inclinação vestibular e extrusão.

MARTINS $^{22}$ (1997) notou que, com o crescimento, a maxila mantém seu relacionamento espacial com a base do crânio, embora cresça em comprimento. A mandíbula por sua vez, cresce tanto em comprimento, como avança anteriormente em relação à base do crânio, conduzindo a uma melhora da relação maxilomandibular, com redução do valor de ANB. Os incisivos superiores mantém sua inclinação com o crescimento, porém com extrusão e protrusão e os molares superiores mesializam e extruem mas com pequena verticalização. Os incisivos inferiores já mostram um ligeiro aumento da inclinação vestibular, acompanhado de 
MALTAGLIATI, L. A.; HENRIQUES, J. F. C.; ALMEIDA, R. R.; FREITAS, M. R.; PINZAN, A. Estudo comparativo das alterações dentoesqueléticas da má-oclusão de Classe II, $1^{\text {a }}$ divisão de Angle, nos jovens sem tratamento e nos submetidos a dois tipos de aparelhos ortodônticos. Rev Odontol Univ São Paulo, n. 13, v. 4, p. 407-416, out./dez. 1999.

extrusão e protrusão, enquanto que os molares inferiores extruem e mesializam.

\section{Tratamento da má-oclusão de Classe II, 1 a divisão}

\section{Aparelho removivel conjugado à ancoragem extrabucal}

O primeiro que originalmente utilizou um aparelho extrabucal inserido em tubos soldados a grampos de aparelhos removiveis, foi McCALLIN ${ }^{21}$ (1953). Posteriormente, THUROW ${ }^{24}$ (1975) preocupando-se com os efeitos secundários indesejáveis e a sobrecarga que os molares sofriam, em virtude das forças extrabucais pesadas, desenvolveu um aparelho destinado à correção das más-oclusões de Classe II, $1^{\text {a }}$ divisão. Verificou que a desoclusão promovida pelo recobrimento oclusal possibilitou uma distribuição uniforme da força por todo o arco dentário superior, promovendo um controle vertical eficiente. Obteve uma restrição do deslocamento ântero-inferior do complexo maxilar, com distalização dos dentes posteriores e um controle de inclinação dos anteriores.

JOFFE; JACOBSON ${ }^{20}$ (1979), incorporaram um arco vestibular à placa de acrílico, com o propósito de permitir pequenos ajustes de inclinação dos incisivos superiores. CALDWELL; HYMAS; TIMM ${ }^{4}$ (1984), observaram uma restrição do crescimento maxilar para frente e para baixo, melhorando a relação maxilomandibular. Não houve alterações significantes no padrão de crescimento e ocorreu um aumento da altura facial ântero-inferior. Constataram uma redução do trespasse vertical e do horizontal e a verticalização dos incisivos superiores, acompanhada de intrusão. Os molares superiores distalizaram, aumentaram a inclinação distal e mantiveram sua posição vertical, enquanto os inferiores verticalizaram, mesializaram e extruíram.

HENRIQUES et al. ${ }^{16}$ (1991) propuseram o emprego do parafuso expansor para ajustes laterais e o arco vestibular para pequenos movimentos de inclinação dos incisivos superiores, selecionando a região dos pré-molares para o ponto de inserção do arco extrabucal. Convencionaram chamar o aparelho "AEB conjugado" e com ele obtiveram um efeito de restrição do crescimento maxilar. Os incisivos superiores foram inclinados para lingual e os inferiores sofreram pequena verticalização. O controle vertical pôde ser demonstrado pelas alterações insignificantes no padrão de crescimento e no pequeno aumento observado da altura facial ântero-inferior.

Nesse mesmo ano, HENRIQUES; FREITAS; SANTOS PINTO ${ }^{14}$ (1991) revelaram que a correção da má-oclusão de Classe II com o AEB conjugado ocorreu em virtude da redução da velocidade de crescimento maxilar, enquanto as demais estruturas do complexo craniofacial mantiveram seu curso normal de desenvolvimento. HENRIQUES ${ }^{13}$ (1993) constatou restrição significante da maxila, melhorando a relação maxilomandibular e observou que o padrão de crescimento não foi alterado. Os incisivos superiores sofreram inclinação para palatino, já os inferiores não foram influenciados pelo tratamento. Os molares superiores por sua vez, foram distalizados com movimento de coroa e raiz nessa direção.

ÜNER; EROGLU ${ }^{25}$ (1996), também observaram melhora dos trespasses horizontal e vertical e redução do prognatismo maxilar. Os molares evoluíram para uma relação de oclusão normal e a altura dentoalveolar da maxila diminuiu significantemente. Para MARTINS ${ }^{22}$ (1997), ocorre uma restrição do crescimento anterior da maxila, enquanto a mandíbula apresenta crescimento normal. Os incisivos superiores inclinam-se para palatino e extruem; os molares superiores são distalizados, aumentando a inclinação distal. HENRIQUES et al. ${ }^{16}$ (1997), denotaram restrição do crescimento anterior maxilar e melhora do relacionamento maxilomandibular. A sobremordida profunda foi atenuada e o padrão de crescimento mostrou-se não influenciável pelo tratamento.

\section{Aparelho fixo associado à ancoragem extrabucal cervical}

A associação da ancoragem extrabucal com o aparelho fixo foi realizada por JARABAK ${ }^{19}$ (1953). $\mathrm{O}$ arco facial empregado era em forma de "J", acoplado em ganchos na distal dos caninos. De acordo com CREEKMORE ${ }^{7}$ (1967), a utilização do aparelho fixo associado à ancoragem extrabucal reduz a discrepância ântero-posterior das bases ósseas. Os incisivos superiores e inferiores são movimentados para distal e o ângulo do plano mandibular e a altura facial anterior também aumentam.

FISCHER $^{12}$ (1980), fez uso da ancoragem extrabucal cervical para a obtenção da relação molar normal. Os resultados estabeleceram que esse método de tratamento acarreta uma rotação mandi- 
MALTAGLIATI, L. A.; HENRIQUES, J. F. C.; ALMEIDA, R. R.; FREITAS, M. R.; PINZAN, A. Estudo comparativo das alterações dentoesqueléticas da má-oclusão de Classe II, $1^{a}$ divisão de Angle, nos jovens sem tratamento e nos submetidos a dois tipos de aparelhos ortodônticos. Rev Odontol Univ São Paulo, n. 13, v. 4, p. 407-416, out./dez. 1999.

bular para baixo e para trás de forma significante.

BOLMGREN; MOSHIRI ${ }^{2}$ (1986), observaram um efeito de retrusão ou de inibição do crescimento maxilar, acompanhada de uma inclinação lingual dos incisivos superiores. O tratamento pareceu não influenciar significantemente o posicionamento dos dentes inferiores.

Já CANGIALOSI et al. ${ }^{5}$ (1988), notaram que o ângulo do plano mandibular não modificou significantemente. Os molares superiores extruíram e mesializaram, assim como os inferiores. Os incisivos superiores verticalizaram e os inferiores vestibularizaram. Tanto a altura anterior superior como a inferior aumentaram.

PAPAIOANNOU; PAPAIOANNOU ${ }^{23}$ (1994), destacaram que existe uma diminuição do tamanho ântero-posterior da maxila e aumento do tamanho da mandíbula, culminando em uma relação maxilomandibular mais harmônica. A altura facial ântero-inferior também aumenta ao final do tratamento.

Os resultados da pesquisa de ELMS; BUSCHANG; ALEXANDER ${ }^{10}$ (1996), revelaram uma sensivel diminuição do valor do ângulo ANB, primariamente em decorrência da redução do valor do SNA. Ocorreu extrusão dos molares e incisivos superiores e inferiores e, enquanto os incisivos superiores mantiveram suas inclinações, os inferiores foram vestibularizados. O ângulo do plano mandibular não alterou significantemente durante o tratamento.

\section{PROPOSIÇÃO}

A avaliação dos aparelhos ortodônticos e ortopédicos necessita da comparação com um grupo controle, para diferenciar as alterações que decorrem do tratamento, daquelas inerentes ao processo de crescimento e desenvolvimento facial. Propusemos analisar cefalometricamente as telerradiografias, em norma lateral de setenta e cinco pacientes, com a finalidade de avaliar as alterações dentoesqueléticas da má-oclusão de Classe II, $1^{\text {a }}$ divisão com e sem tratamento, em relação a: padrão do crescimento facial; maxila; mandíbula, relação maxilomandibular e dentes, além do dimorfismo sexual.

\section{MATERIAL E MÉTODOS}

A amostra foi composta de 150 telerradiografias em norma lateral, de 75 pacientes de ambos os se- xos, pertencentes ao acervo da Disciplina de Ortodontia da Faculdade de Odontologia de Bauru, da Universidade de São Paulo. Todos apresentavam as seguintes características: 1) má-oclusão de Classe II, $1^{\text {a }}$ divisão de Angle, determinada pela avaliação dos modelos de estudo e pela presença de trespasse horizontal aumentado; 2) procediam do curso de pós-graduação em Ortodontia; 3) leucodermas, descendentes de italianos, portugueses e espanhóis.

A amostra foi dividida em três grupos, com 12 jovens do sexo feminino e 13 do masculino:

- Grupo 1 - controle, caracterizado por jovens apresentando má-oclusão de Classe II, $1^{\text {a }}$ divisão de Angle, sem tratamento, acompanhados longitudinalmente por um período médio de 3,36 anos (idade inicial de 9,35 anos e final de 12,68 anos).

- Grupo 2 - Tratado com o aparelho removível conjugado à ancoragem extrabucal, apresentando idade média inicial de 9,83 anos e final de 11,08 anos, e

- Grupo 3 - Tratado com ortodontia corretiva sem extrações e ancoragem extrabucal cervical, cuja idade média inicial foi de 12,08 anos e final de 13,91 anos.

As telerradiografias utilizadas foram tomadas em norma lateral, com a oclusão o mais próximo possivel da relação cêntrica. Obedeceu-se as normas para a técnica de obtenção e de processamento, recomendadas pela Disciplina de Radiologia da Faculdade de Odontologia de Bauru, da Universidade de São Paulo. Para cada radiografia, adaptou-se uma folha de papel "ultraphan", de $17,5 \mathrm{~cm}$ de comprimento por $17,5 \mathrm{~cm}$ de largura e 0,07 $\mathrm{mm}$ de espessura. Realizou-se o cefalograma em um negatoscópio, em ambiente escurecido, emoldurado com cartolina preta. Os pontos cefalométricos foram demarcados e inseridos em um computador, com o auxílio de uma mesa digitalizadora; os traçados foram realizados e as mensurações obtidas no "software" de Ortodontia Dentofacial Planner 7.0 (Figuras 1 e 2).

\section{RESULTADOS}

Os resultados da avaliação cefalométrica das alterações dentoesqueléticas da má-oclusão de Classe II, $1^{a}$ divisão com e sem tratamento foram dispostos em tabelas, de acordo com os testes estatísticos empregados. Os dados obtidos em todas as medidas cefalométricas para os três grupos fo- 
MALTAGLIATI, L. A.; HENRIQUES, J. F. C.; ALMEIDA, R. R.; FREITAS, M. R.; PINZAN, A. Estudo comparativo das alterações dentoesqueléticas da má-oclusão de Classe II, $1^{\text {a }}$ divisão de Angle, nos jovens sem tratamento e nos submetidos a dois tipos de aparelhos ortodônticos. Rev Odontol Univ São Paulo, n. 13, v. 4, p. 407-416, out./dez. 1999.

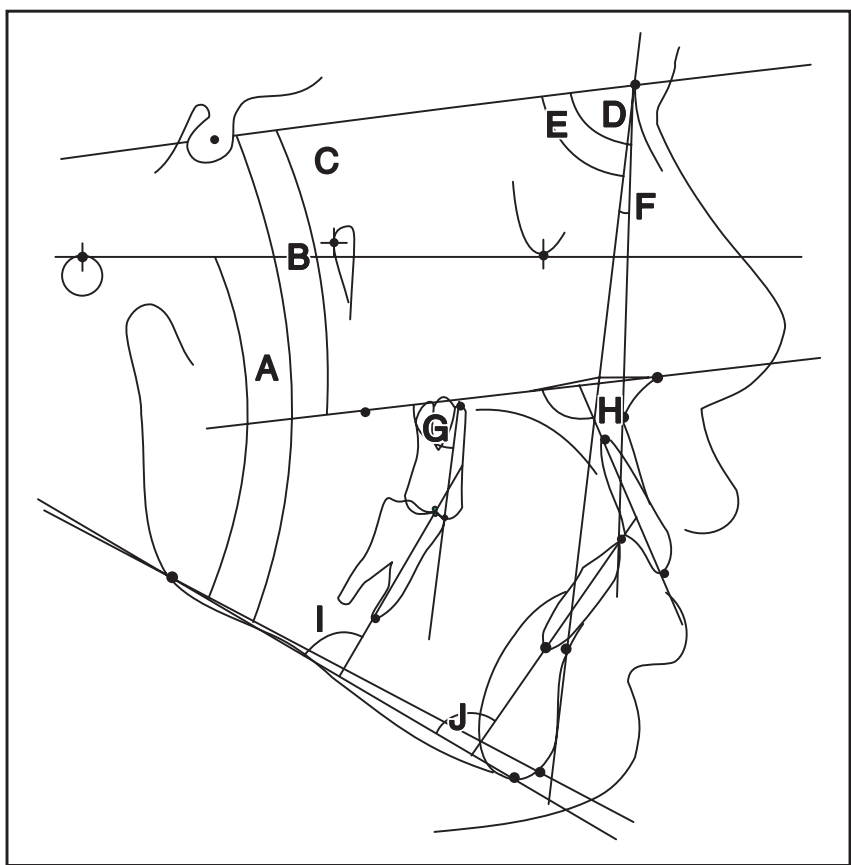

FIGURA 1 - Medidas angulares esqueléticas e dentárias empregadas. A) FMA; B) SN.GoGn; C) SN.PP; D) SNA;

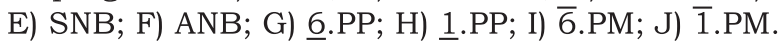

ram computados pela análise de variância, para a verificação de alterações de comportamento entre eles (Tabela 1). Os valores que apresentaram-se estatisticamente distintos foram submetidos ao teste de Tukey, no intuito de identificar aqueles que foram responsáveis pela rejeição da hipótese nula, de igualdade entre os grupos (Tabelas 2, 3 e 4). O valor crítico foi construído ao nível de significância de $\mathrm{p}<0,05$ e 0,01 para todas as análises empregadas.

\section{DISCUSSÃO}

A má-oclusão de Classe II constitui-se, sem dúvida, em um dos temas mais pesquisados e comentados na Ortodontia. A freqüência com que se apresenta e a grande variabilidade, características principais dessa entidade clínica, são em parte, responsáveis pela vasta literatura pertinente, de tal sorte que desenvolveram-se vários métodos de correção e aparelhos com o propósito de solver essa discrepância dentofacial, seja interceptando-a ou corrigindo-a. Não obstante ocorrerem divergências dentre os conceitos acerca dos tratamentos, é de comum acordo entre os pesquisa-

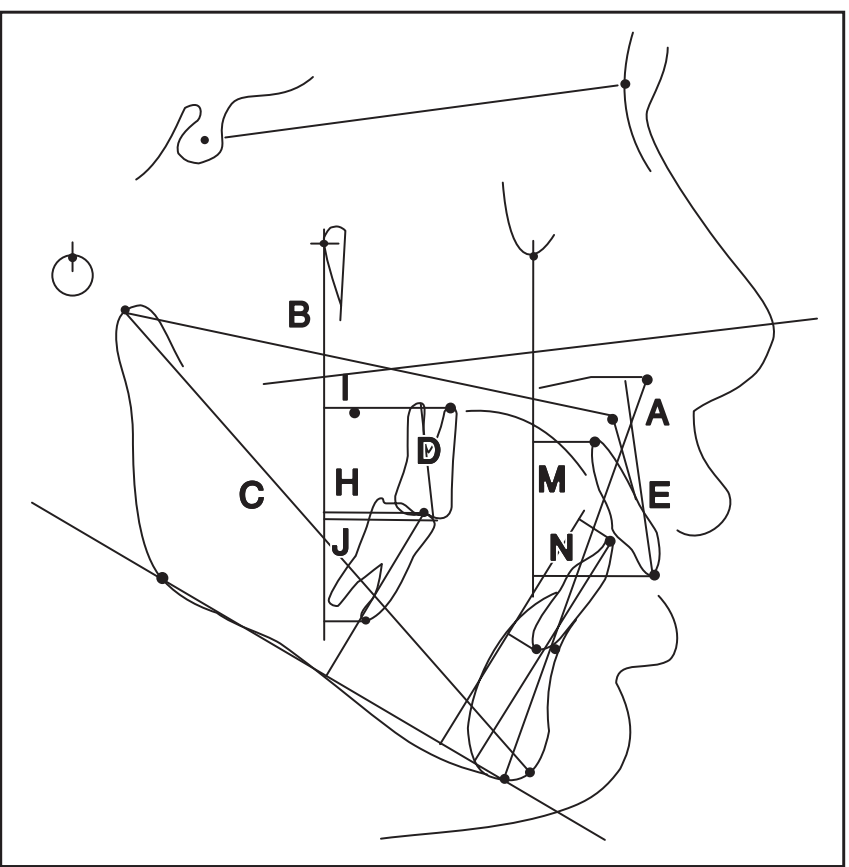

FIGURA 2 - Medidas lineares esqueléticas e dentárias empregadas. A) ENA-Me; B) Co-A; C) Co-Gn; D) $\underline{6}-\mathrm{PP}$; E) 1 -PP; F) б-PM; G) $1-P M$; H) $\underline{6}$-Pt.perp; I) $\underline{6}$-Pt.perp; J) $\overline{\overline{6}}$-Pt.perp; K) $\overline{6}$ '-Pt.perp; L) 1 -Or.perp; M) $\underline{1}$ '-Or.perp; N) $\overline{1}$-Si.perp; O) $\overline{1}$ '-Si.perp.

dores que a intervenção oportuna, durante os períodos de crescimento ativo, conduz aos resultados mais promissores. O padrão de crescimento facial exibiu tendência de fechamento sem importância dos ângulos, confirmado pelos trabalhos compulsados $^{3,24}$ nos jovens sem tratamento. Nos submetidos ao tratamento com o aparelho removivel conjugado à ancoragem extrabucal, assim como com a terapia ortodôntica fixa, o padrão de crescimento não alterou significantemente, apresentando um comportamento semelhante nos três grupos (Tabela 1). Entretanto, para a altura facial ântero-inferior, o grupo 2 apresentou um aumento estatisticamente menor que o dos grupos controle (Tabela 2) e tratado com o aparelho fixo e ancoragem extrabucal cervical (Tabela 4), o que também foi comprovado por MARTINS ${ }^{22}$ (1997) denotando um controle vertical eficiente desse aparelho.

As grandezas que avaliaram o comportamento maxilar (SNA e Co-A) evidenciaram restrição do crescimento anterior da maxila nos grupos tratados, pelo comportamento estatisticamente diferente do grupo controle (Tabelas 2 e 3). Vários autores também encontraram restrição da maxila nos gru- 
MALTAGLIATI, L. A.; HENRIQUES, J. F. C.; ALMEIDA, R. R.; FREITAS, M. R.; PINZAN, A. Estudo comparativo das alterações dentoesqueléticas da má-oclusão de Classe II, $1^{\text {a }}$ divisão de Angle, nos jovens sem tratamento e nos submetidos a dois tipos de aparelhos ortodônticos. Rev Odontol Univ São Paulo, n. 13, v. 4, p. 407-416, out./dez. 1999.

TABELA 1 - Análise de variância dos três grupos para as diferenças das médias iniciais e finais.

\begin{tabular}{|c|c|c|c|c|c|}
\hline \multicolumn{6}{|c|}{ Diferenças das médias das alterações } \\
\hline & Grupo 1 & Grupo 2 & Grupo 3 & $\mathrm{~F}$ & Sig. \\
\hline FMA & $-0,61$ & 0,09 & 0,02 & 1,40420 & n.s. \\
\hline SN.GoGn & $-0,47$ & $-0,37$ & $-0,08$ & 0,35989 & n.s. \\
\hline SN.PP & 0,27 & 0,96 & 1,10 & 1,35055 & n.s. \\
\hline ENA-Me & 3,36 & 0,99 & 3,08 & 5,74543 & s. ${ }^{* *}$ \\
\hline SNA & 0,36 & $-0,84$ & $-1,50$ & 8,01898 & s. ${ }^{* *}$ \\
\hline Co-A & 4,92 & 0,36 & 1,26 & 36,14914 & s. ${ }^{* *}$ \\
\hline SNB & 0,57 & 0,70 & 0,53 & 0,07406 & n.s. \\
\hline Co-Gn & 7,54 & 2,57 & 5,86 & 18,58174 & s. $* *$ \\
\hline ANB & $-0,19$ & $-1,53$ & $-2,03$ & 15,08179 & s.** \\
\hline 6.PP & 5,51 & $-0,73$ & 3,29 & 7,33713 & s. ${ }^{* *}$ \\
\hline 1.PP & 1,14 & $-5,85$ & 0,04 & 7,01154 & s.** \\
\hline$\overline{6} . \mathrm{PM}$ & $-2,14$ & $-1,13$ & $-5,71$ & 4,39494 & s. $* *$ \\
\hline 1.PM & 0,12 & $-1,30$ & 2,60 & 4,61625 & s.** \\
\hline 6-PP & 2,99 & 0,80 & 2,39 & 11,26608 & s.** \\
\hline$\underline{1}-\mathrm{PP}$ & 1,56 & 0,43 & 0,26 & 5,05436 & s. ${ }^{* *}$ \\
\hline$\overline{6}-\mathrm{PM}$ & 1,30 & 0,90 & 1,66 & 1,18247 & n.s. \\
\hline$\overline{1}-\mathrm{PM}$ & 2,56 & 0,95 & 0,74 & 7,55094 & s. ${ }^{* *}$ \\
\hline 6-Pt.perp & 3,08 & $-0,34$ & 0,47 & 8,75737 & s. ${ }^{* *}$ \\
\hline$\underline{6}$ '-Pt.perp & 1,66 & 0,40 & $-0,18$ & 4,39434 & s.** \\
\hline$\overline{6}$-Pt.perp & 3,29 & 2,58 & 2,10 & 1,27124 & n.s. \\
\hline$\overline{6}$ '-Pt.perp & 3,79 & 2,86 & 4,11 & 1,07083 & n.s. \\
\hline 1-Or.perp & 2,31 & $-2,18$ & $-1,21$ & 16,74414 & s.** \\
\hline$\underline{1}$ '-Or.perp & 2,05 & 0,63 & $-0,84$ & 14,44079 & s. ${ }^{* *}$ \\
\hline$\overline{1}$-Si.perp & $-0,32$ & $-0,57$ & 0,23 & 1,04934 & n.s. \\
\hline$\overline{1}$ '-Si.perp & $-0,52$ & $-0,01$ & $-0,50$ & 1,61539 & n.s. \\
\hline
\end{tabular}

*Significante para $\mathrm{p}<0,05$.

**Significante para $\mathrm{p}<0,01$.

pos experimentais para os valores de SNA no grupo $2^{6,13,17,19}$ e grupo $3^{2,7,9,12}$ e para os valores de Co-A no grupo 2 e $3^{19,25}$.

Quanto à mandíbula, o crescimento em relação à base do crânio foi similar entre os jovens tratados e não tratados. Em nossos resultados, os valo-
TABELA 2 - Teste de Tukey para as alterações estatisticamente significantes entre os grupos 1 e 2 .

\begin{tabular}{|c|c|c|c|c|}
\hline & \multicolumn{2}{|c|}{ Grupos (médias) } & Teste de Tukey & Sig. \\
\hline & 1 & 2 & $\mathrm{p}$ & \\
\hline ENA-Me & 3,36 & 0,99 & 0,007754 & s. $* *$ \\
\hline SNA & 0,36 & $-0,84$ & 0,033518 & s.* \\
\hline Co-A & 4,92 & 0,36 & 0,000111 & s. $* *$ \\
\hline Co-Gn & 7,54 & 2,57 & 0,000111 & s. $* *$ \\
\hline ANB & $-0,19$ & $-1,53$ & 0,000776 & s. $* *$ \\
\hline 1.PP & 1,14 & $-5,85$ & 0,002509 & s. $* *$ \\
\hline 6.PP & 5,51 & $-0,73$ & 0,001027 & s. $* *$ \\
\hline 1.PM & 0,12 & $-1,30$ & 0,522878 & n.s. \\
\hline$\overline{6} . \mathrm{PM}$ & $-2,14$ & $-1,13$ & 0,807804 & n.s. \\
\hline 6-PP & 2,99 & 0,80 & 0,000159 & s. $* *$ \\
\hline$\underline{1-P P}$ & 1,56 & 0,43 & 0,034171 & s.* \\
\hline$\overline{1}-\mathrm{PM}$ & 2,56 & 0,95 & 0,006868 & s. $* *$ \\
\hline 6-Pt.perp & 3,08 & $-0,34$ & 0,000531 & s. $* *$ \\
\hline$\underline{6}^{\prime}$-Pt.perp & 1,66 & 0,40 & 0,123241 & n.s. \\
\hline 1-Or.perp & 2,31 & $-2,18$ & 0,000112 & s. $* *$ \\
\hline 1 '-Or.perp & 2,05 & 0,63 & 0,027323 & s. ${ }^{*}$ \\
\hline
\end{tabular}

*Significante para $\mathrm{p}<0,05$.

**Significante para $\mathrm{p}<0,01$.

res também não alcançaram diferença estatística (Tabela 1). Para os valores de Co-Gn, o grupo 2 apresentou o menor aumento, em decorrência do tempo de observação desse grupo, que igualmente foi menor.

A discrepância maxilomandibular, segundo as pesquisas compulsadas, possui melhora insignificante nas más-oclusões de Classe II, $1^{a}$ divisão sem tratamento ${ }^{4}$, o que foi constatado nessa pesquisa, ao passo que frente ao tratamento, a melhora foi significativa ${ }^{6,7,9,12,13,17}$.

Dentariamente, observando a inclinação de molares e incisivos em relação aos planos palatino e mandibular, observamos um aumento da inclinação mesial e vestibular dos molares e incisivos superiores em decorrência do crescimento no grupo 1 , resultado este sustentado por vários auto$\mathrm{res}^{24}$, embora alguns defendam que os incisivos superiores inclinam-se para lingual ${ }^{10}$ e que a sua 
MALTAGLIATI, L. A.; HENRIQUES, J. F. C.; ALMEIDA, R. R.; FREITAS, M. R.; PINZAN, A. Estudo comparativo das alterações dentoesqueléticas da má-oclusão de Classe II, $1^{\text {a }}$ divisão de Angle, nos jovens sem tratamento e nos submetidos a dois tipos de aparelhos ortodônticos. Rev Odontol Univ São Paulo, n. 13, v. 4, p. 407-416, out./dez. 1999.

TABELA 3 - Teste de Tukey para as alterações estatisticamente significantes entre os grupos 1 e 3 .

\begin{tabular}{|c|c|c|c|c|}
\hline & \multicolumn{2}{|c|}{ Grupos (médias) } & Teste de Tukey & Sig. \\
\hline & 1 & 3 & $\mathrm{p}$ & \\
\hline ENA-Me & 3,36 & 3,08 & 0,928686 & n.s. \\
\hline SNA & 0,36 & $-1,50$ & 0,000631 & $\mathrm{~s}{ }^{* *}$ \\
\hline Co-A & 4,92 & 1,26 & 0,000111 & $\mathrm{~s} .^{* *}$ \\
\hline Co-Gn & 7,54 & 5,86 & 0,111301 & n.s. \\
\hline ANB & $-0,19$ & $-2,03$ & 0,000114 & $\mathrm{s.} * *$ \\
\hline 1.PP & 1,14 & 0,36 & 0,847653 & n.s. \\
\hline 6.PP & 5,51 & 3,29 & 0,375681 & n.s. \\
\hline 1.PM & 0,12 & 2,60 & 0,143142 & n.s. \\
\hline$\overline{6} . \mathrm{PM}$ & $-2,14$ & $-5,71$ & 0,078347 & n.s. \\
\hline$\underline{6}-\mathrm{PP}$ & 2,99 & 2,39 & 0,424044 & n.s. \\
\hline$\underline{1-P P}$ & 1,56 & 0,26 & 0,012925 & s.* \\
\hline$\overline{1}-\mathrm{PM}$ & 2,56 & 0,74 & 0,002046 & $\mathrm{~s} . * *$ \\
\hline 6-Pt.perp & 3,08 & 0,47 & 0,008743 & $\mathrm{~s}{ }^{* *}$ \\
\hline$\underline{6}$ '-Pt.perp & 1,66 & $-0,18$ & 0,013663 & s. ${ }^{*}$ \\
\hline 1-Or.perp & 2,31 & $-1,21$ & 0,000249 & s. ${ }^{* *}$ \\
\hline 1'-Or.perp & 2,05 & $-0,84$ & 0,000113 & s. ${ }^{* *}$ \\
\hline
\end{tabular}

*Significante a $\mathrm{p}<0,05$.

**Significante a $\mathrm{p}<0,01$.

inclinação relativa é mantida ${ }^{3}$. Com o aparelho removivel conjugado à ancoragem extrabucal, foi promovida uma inclinação distal dos molares ${ }^{6,17} \mathrm{e}$ lingual dos incisivos ${ }^{6,13,17,22}$. A terapia ortodôntica fixa causou uma inclinação mesial dos molares, diferentemente dos resultados de DERRINGER ${ }^{9}$ (1990) que observou movimento distal. Tal resultado, entretanto, depende de fatores como a linha de ação da força extrabucal entre outros. Os incisivos denotaram alteração insignificante de sua inclinação, o que foi confirmado por ELMS; BUSCHANG; ALEXANDER $^{10}$ (1996) provavelmente devido à mecânica utilizada, apesar das pesquisas de apoio observarem inclinação lingual ${ }^{7,22}$.

Os molares inferiores apresentaram verticalização em todos os grupos, corroborando com CARTER $^{6}$ (1987). No grupo 3, a verticalização foi significantemente maior, o que se deveu aos processos de alinhamento e nivelamento do tra-
TABELA 4 - Teste de Tukey para as alterações estatisticamente significantes entre os grupos 2 e 3.

\begin{tabular}{|c|c|c|c|c|}
\hline & \multicolumn{2}{|c|}{ Grupos (médias) } & Teste de Tukey & Sig. \\
\hline & 2 & 3 & $\mathrm{p}$ & \\
\hline ENA-Me & 0,99 & 3,08 & 0,021071 & s. ${ }^{*}$ \\
\hline SNA & $-0,84$ & $-1,50$ & 0,351680 & n.s. \\
\hline Co-A & 0,36 & 1,26 & 0,264323 & n.s. \\
\hline Co-Gn & 2,57 & 5,86 & 0,000611 & s. ${ }^{* *}$ \\
\hline ANB & $-1,53$ & $-2,03$ & 0,329092 & n.s. \\
\hline 1.PP & $-5,85$ & 0,36 & 0,012426 & s. ${ }^{*}$ \\
\hline 6.PP & $-0,73$ & 3,29 & 0,045380 & s. ${ }^{*}$ \\
\hline 1.PM & $-1,30$ & 2,60 & 0,010297 & s. ${ }^{*}$ \\
\hline$\overline{6} . \mathrm{PM}$ & $-1,13$ & $-5,71$ & 0,016886 & s. ${ }^{*}$ \\
\hline 6-PP & 0,80 & 2,39 & 0,003912 & s. ${ }^{* *}$ \\
\hline 1-PP & 0,43 & 0,26 & 0,927681 & n.s. \\
\hline 1-PM & 0,95 & 0,74 & 0,913439 & n.s. \\
\hline 6-Pt.perp & $-0,34$ & 0,47 & 0,615003 & n.s. \\
\hline 6'-Pt.perp & 0,40 & $-0,18$ & 0,633401 & n.s. \\
\hline 1-Or.perp & $-2,18$ & $-1,21$ & 0,465461 & n.s. \\
\hline 1'-Or.perp & 0,63 & $-0,84$ & 0,021253 & s.* \\
\hline
\end{tabular}

*Significante a $\mathrm{p}<0,05$.

**Significante a $\mathrm{p}<0,01$.

tamento desse grupo (Tabelas 3 e 4). Já os incisivos inferiores comportaram-se de forma divergente. Enquanto no grupo controle houve alterações sem importância estatística, no grupo 2, esses dentes foram inclinados para lingual, contrariando os trabalhos de JOFFE; JACOBSON ${ }^{20}$ (1979) e MARTINS $^{22}$ (1997) porém concordando com os demais $^{6,13,19}$ e, no grupo 3 , foram vestibularizados, o que vai ao encontro de CANGIALOSI et al. ${ }^{5}$ (1998) e ELMS; BUSCHANG; ALEXANDER ${ }^{10}$ (1996).

A extrusão dos molares superiores foi significantemente menor no grupo tratado com o aparelho removivel conjugado à ancoragem extrabucal (Tabelas 2 e 4). Essa restrição de extrusão foi confirmada por vários autores que salientaram que não só os molares são impedidos de desenvolverem seu potencial de crescimento vertical, como também todo o arco dentário superior ${ }^{6,13}$. O mesmo comportamento foi seguido pelos incisivos supe- 
MALTAGLIATI, L. A.; HENRIQUES, J. F. C.; ALMEIDA, R. R.; FREITAS, M. R.; PINZAN, A. Estudo comparativo das alterações dentoesqueléticas da má-oclusão de Classe II, $1^{a}$ divisão de Angle, nos jovens sem tratamento e nos submetidos a dois tipos de aparelhos ortodônticos. Rev Odontol Univ São Paulo, n. 13, v. 4, p. 407-416, out./dez. 1999.

riores do grupo tratado com o aparelho fixo e ancoragem extrabucal cervical, controlando o posicionamento vertical desses dentes por meio da acentuação da curva de Spee durante a fase de nivelamento. A extrusão dos molares inferiores foi constatada em todos os grupos, sem diferença estatística entre eles, denotando pouca influência dos tratamentos no posicionamento vertical desses dentes (Tabela 1), corroborando com os trabalhos pesquisados ${ }^{16,26}$. Entretanto, foi alcançada significância estatística quando comparamos o grupo não tratado com os tratados em relação à extrusão dos incisivos inferiores. Esta foi maior para o grupo controle, evidenciando um controle vertical dos aparelhos empregados nos grupos $2 \mathrm{e}$ 3 (Tabelas 2 e 3 ).

O posicionamento ântero-posterior de molares e incisivos foi verificado ao nível da coroa e da raiz. Sem tratamento, os molares e incisivos superiores acompanharam o deslocamento da maxila, exibindo uma trajetória para frente e para baixo tanto de coroa como de raiz. Esse comportamento foi similar tanto nos trabalhos que avaliaram o movimento dos molares ${ }^{7,9,22,26}$ como naqueles que examinaram os incisivos ${ }^{9,15,22}$. No grupo 2, a atuação do aparelho removivel causou movimento distal e lingual das coroas e mesial e vestibular das raízes dos molares $^{4,9,10,14,19,22}$ e incisivos superiores ${ }^{4,10,16,19,22}$. No grupo 3, o aparelho fixo empregado promoveu pequeno movimento mesial da coroa dos molares superiores e distal da raiz. Já os incisivos superiores apresentaram movimento distal tanto de coroa como de raiz. No arco dentário inferior, os molares apresentaram movimento mesial tanto da coroa como da raiz, porém maior dessa última estrutura, o que causa o efeito de verticalização. Esse comportamento foi observado nos três grupos, sem diferença estatística entre eles (Tabela 1), o que está de acordo com os estudos da literatura ${ }^{9,19,20,22,26}$. A manifestação das alterações ântero-posteriores da coroa e do ápice dos incisivos inferiores dos pacientes não tratados traduziu-se por uma lingualização, discretamente menor do ápice. Muita divergência, entretanto, é encontrada entre os autores. DERRINGER ${ }^{9}$ (1990) e MARTINS ${ }^{22}$ (1997) encontraram movimento vestibular de coroa e raiz. No grupo tratado com o aparelho removivel conjugado à ancoragem extrabucal, no entanto, trabalhos como os de CALDWELL; HYMAS; TIMM ${ }^{4}$ (1998) e HENRIQUES et al. ${ }^{14}$ (1991) obtiveram resultado semelhante ao desta pesquisa onde coroa e raiz movimentaram-se para lingual, com maior expressi- vidade para a coroa. E, no grupo 3, a utilização do aparelho fixo refletiu em um movimento vestibular de coroa e lingual de raiz, confirmando os achados de DERRINGER ${ }^{9}$ (1990).

A ausência de dimorfismo sexual para a maioria das medidas cefalométricas, transparece a homogeneidade de comportamento entre os sexos nos grupos avaliados. Vários autores ${ }^{1,16,18,26}$ defendem a não ocorrência de dimorfismo sexual, afirmando que o mesmo só é detectável em idades mais avançadas, em média, a partir dos 15 ou 16 anos.

\section{CONCLUSÕES}

- O padrão do crescimento facial apresentou pequenas modificações, com predominância do componente horizontal no grupo 1. A altura facial ântero-inferior aumentou em todos os grupos, porém no grupo 2, foi significantemente menor.

- A maxila apresentou um crescimento ântero-inferior contínuo no grupo sem tratamento, com aumento dos valores de Co-A e SNA, enquanto que, nos grupos tratados, exibiu restrição significante do seu crescimento anterior.

- A mandíbula expressou crescimento anterior similar nos três grupos (SNB), com menor aumento do valor de Co-Gn para o grupo 2 .

- A relação maxilomandibular, no grupo controle, obteve melhora insignificante, promovendo a manutenção da discrepância esquelética da má-oclusão de Classe II, $1^{a}$ divisão. Nos grupos tratados, houve sensivel melhora, com diminuição significante da grandeza ANB.

- Os molares e incisivos superiores apresentaram, no grupo 1, mesialização, extrusão e aumento da inclinação mesial e vestibular, respectivamente. No grupo 2, foram retruídos, exibindo inclinação distal dos molares e lingual dos incisivos e, no grupo 3, houve inclinação mesial dos molares e manutenção da inclinação dos incisivos superiores. Houve restrição da extrusão desses dentes para ambos os grupos experimentais. Os molares inferiores exibiram verticalização, mesialização de coroa e raiz e extrusão nos três grupos. Em relação aos incisivos inferiores, estes movimentaram-se para vestibular no grupo 1 e para lingual nos grupos 2 e 3, com aumento da inclinação vestibular nos grupos 1 e 3 e lingual no grupo 2 . Houve restrição de extrusão nos grupos experimentais em comparação ao controle. 
MALTAGLIATI, L. A.; HENRIQUES, J. F. C.; ALMEIDA, R. R.; FREITAS, M. R.; PINZAN, A. Estudo comparativo das alterações dentoesqueléticas da má-oclusão de Classe II, $1^{\text {a }}$ divisão de Angle, nos jovens sem tratamento e nos submetidos a dois tipos de aparelhos ortodônticos. Rev Odontol Univ São Paulo, n. 13, v. 4, p. 407-416, out./dez. 1999.

MALTAGLIATI, L. A.; HENRIQUES, J. F. C.; ALMEIDA, R. R.; FREITAS, M. R.; PINZAN, A. Comparative study of dentoskeletal changes in untreated Class II, division 1 malocclusions and in those treated with two types of orthodontic appliances. Rev Odontol Univ São Paulo, n. 13, v. 4, p. 407-416, out./dez. 1999.

The purpose of this study was to compare the skeletal and dental changes of the Class II, division 1 malocclusions with and without treatment. Seventy five patients were divided in three groups: control, treated with a modified maxillary splint and treated with fixed appliance and Kloehn headgear, each one having thirteen males and twelve females. The cephalometric radiographs were traced and analyzed by means of the "Dentofacial Planner" software. The results showed that there is little change in the pattern of growth and that the anteroinferior facial height increases in the three groups. There is no significant improvement in the maxillomandibular relationship in the control group, while in the treatment groups, the maxilla seemed to be retracted with a significant decrease in the ANB angle. The dentoalveolar changes showed that the appliance used in the second group is efficient in controlling the vertical extrusion of the upper teeth. In both treated groups, they are moved distally, leading to a normal molar relationship and the reduction of the overjet. In the controls, however, the teeth continue to develop in an anteroinferior direction, maintaining the Class II characteristics.

UNITERMS: Orthodontics; Orthodontic appliances; Maloclusion, Angle Class II.

\section{REFERÊNCIAS BIBLIOGRÁFICAS}

1. ARIZA DIAS, M. C.; PINZAN, A.; HENRIQUES, J. F. C. Avaliação comparativa do crescimento maxilomandibular em crianças leucodermas brasileiras, com oclusão normal, utilizando as medidas Co-A, Co-Gn, AFAI e dif.mand./max. da análise cefalométrica proposta por McNamara Jr. Ortodontia, v. 26, n. 1, p. 14-23, jan./abril 1993.

2. BOLMGREN, G. A.; MOSHIRI, F. Bionator treatment in Class II, division 1. Angle Orthod, v. 56, n. 3, p. 255-262, July 1986.

3. BROADBENT, B. H. A new x-ray technique and its application to orthodontia. Angle Orthod, v. 1, p. 45-66, 1931.

4. CALDWELL, S. F.; HYMAS, A.; TIMM, T. A. Maxillary traction splint: a cephalometric evaluation. Am J Orthod Dentofacial Orthop, v. 85, n. 5, p. 376-384, May 1984.

5. CANGIALOSI, T. J.; MEISTRELL JUNIOR, M. E.; LEUNG, M. A.; KO, J. Y. A cephalometric appraisal of edgewise Class II nonextraction treatment with extra-oral force. Am J Orthod Dentofacial Orthop, v. 93, n. 4, p. 315-324, Apr. 1988.

6. CARTER, N. E. Dentofacial changes in untreated Class II division 1 subjects. Br J Orthod, v. 14, n. 4, p. 225-234, Nov. 1987.

7. CREEKMORE, T. D. Inhibitionor stimulation of the vertical growth of the facial complex, its significance to treatment. Angle Orthod, v. 37, n. 4, p. 285-297, Oct. 1967.

8. DERRINGER, K. A cephalometric study to compare the effects of cervical traction and Andresen therapy in the treatment of Class II division 1 malocclusion Part 1 skeletal changes. Br J Orthod, v. 17, n. 1, p. 33-46, Feb. 1990

9. DERRINGER, K. A cephalometric study to compare the effects of cervical traction and Andresen therapy in the treatment of Class II division 1 malocclusion Part 2 - dentoalveolar changes. Br J Orthod, v. 17, n. 2, p. 89-99, May 1990.

10. ELMS, T. N.; BUSCHANG, P. H.; ALEXANDER, R. G. Long-term stability of Class II, division 1, nonextraction cervical face-bow therapy: II. cephalometric analysis. Am J Orthod Dentofacial Orthop, v. 109, n. 4, p. 386-392, Apr. 1996.

11. ENLOW, D. H.; HANS, M. G. Essentials of facial growth. Philadelphia : W. B. Saunders, 1996. 303 p.

12. FISCHER, B. Treatment of Class II, division 1 (Angle) III. variation and the "individuality hypothesis". Angle Orthod, v. 20, n. 2, p. 116-134, Apr. 1950.

13. HENRIQUES, J. F. C. Estudo cefalométrico comparativo, de três tipos de ancoragem extrabucal, sobre as estruturas dentoesqueléticas, em pacientes com Classe II, $\mathbf{1}^{\text {a }}$ divisão. Bauru, 1993. 166 p. Tese (Livre-Docência) - Faculdade de Odontologia de Bauru, Universidade de São Paulo.

14. HENRIQUES, J. F. C.; FREITAS, M. R.; SANTOS PINTO, C. C. M. Correção de uma má-oclusão de Classe II, $1^{a}$ divisão, com protrusão maxilar, utilizando o arco facial conjugado a um aparelho removivel (AEB conjugado). Ortodontia, v. 24, n. 3, p. 14-18, set./dez. 1991.

15. HENRIQUES, J. F. C. MATAGLIATI, L. A.; FREITAS, M. R.; JANSON, G. R. P.; MALTAGLIATI, A. M. A. Utilização do aparelho removivel conjugado à ancoragem extrabucal para a correção da má-oclusão de Classe II, $1^{\text {a }}$ divisão, com sobremordida profunda. Rev Dent Press Ortodon e Ortoped Maxilar, v. 2, n. 2, p. 12-18, mar./abr. 1997.

16. HENRIQUES, J. F. C. et. al. Modified maxillary splint for Class II, division 1 treatment. J Clin Orthod, v. 25, n. 4, p. 239-245, Apr. 1991.

17. HOFRATH, H. Die Bedeutung der Roentgenfern- und Abstandsaufnahmen für die Diagnostik der Kiefernanomalien. Fortsch Orthod, v. 2, p. 232-58, 1931 apud BRODIE, A.G. On growth pattern of the human head, 
MALTAGLIATI, L. A.; HENRIQUES, J. F. C.; ALMEIDA, R. R.; FREITAS, M. R.; PINZAN, A. Estudo comparativo das alterações dentoesqueléticas da má-oclusão de Classe II, $1^{\text {a }}$ divisão de Angle, nos jovens sem tratamento e nos submetidos a dois tipos de aparelhos ortodônticos. Rev Odontol Univ São Paulo, n. 13, v. 4, p. 407-416, out./dez. 1999.

from the third months to the eight years of life. Am $\mathbf{J}$ Anat, v. 68, p. 209-262, Mar. 1941.

18. JANSON, G. R. P. Estudo longitudinal e comparativo do crescimento facial, dos 13 aos 18 anos de idade, em jovens brasileiros leucodermas utilizando a análise cefalométrica de McNamara Jr. Bauru, 1990. 135 p. Tese (Doutorado) - Faculdade de Odontologia de Bauru, Universidade de São Paulo.

19. JARABAK, J. R. Treatment of Class II, division 1 malocclusion with an upper edgewise appliance and a cervical elastic strap. Angle Orthod, v. 23, n. 2, p. 78-102, Apr. 1953.

20. JOFFE, L.; JACOBSON, A. The maxillary orthopedic splint. Am J Orthod, v. 75, n. 1, p. 54-69, Jan. 1979.

21. McCALLIN, S. G. Extra-oral traction in orthodontics Dent Practit Rec, v. 12, n. 1, p. 25-38, Sept. 1961 apud NICHOLSON, P. T. Extra-oral anchorage to upper removable appliances. Br Dent J, v. 147, n. 2, p. 45-46, July 1979.

22. MARTINS, J. C. R. Avaliação cefalométrica comparativa dos resultados da interceptação da má-oclusão de Classe II, divisão $1^{\text {a }}$ de Angle, efetuados com o apare- lho extrabucal removivel ou com o bionator. Araraquara, 1997. 333 p. Tese (Livre-Docência) - Faculdade de Odontologia de Araraquara, Universidade Estadual Paulista.

23. PAPAIOANNOU, M. O.; PAPAIOANNOU, A. Comparison of treatment results with the edgewise and the Begg approach. J Clin Pediatr Dent, v. 19, n. 1, p. 27-30, Fall 1994.

24. THUROW, R. C. Craniomaxillary orthopedic correction with en masse dental control. Am J Orthod, v. 68, n. 6, p. 601-624, Dec. 1975.

25. ÜNER, O.; EROGLU, E. Y. Effects of a modified maxillary orthopaedic splint: a cephalometric evaluation. Eur J Orthod, v. 18, p. 269-286, 1996.

26. URSI, W. J. S. Crescimento e alterações nas relações mandibulares dos 6 aos 18 anos de idade. Ortodontia, v. 29, n. 1, p. 4-11, jan./abr. 1996.

27. VALE, D. M. V.; MARTINS, D. R. Avaliação cefalométrica das estruturas dentoesqueléticas em jovens portadores de Classe II, divisão 1, brasileiros, leucodermas e de origem mediterrânea. Ortodontia, v. 20, n. 1/2, p. 5-17, 1987. 